\title{
Using Social Media to Support Requirements Gathering When Users are Not Available
}

\author{
Joel Scanlan \\ University of Tasmania \\ joel.scanlan@utas.edu.au
}

\author{
Kristy de Salas \\ University of Tasmania \\ kristy.desalas@utas.edu.au
}

\author{
Daniel Lim \\ University of Tasmania \\ tiongjing.lim@utas.edu.au
}

\author{
Erin Roehrer \\ University of Tasmania \\ erin.roehrer@utas.edu.au
}

\begin{abstract}
The use of mobile health applications has surged in numbers since the advent of smart phones a decade ago. Yet, many mobile applications suffer from low engagement due to poor application design. This could be partially due to the primary users of an eHealth applications being time poor and inaccessible to software developers due to their complex health needs. This study investigated the needs of a complex cohort to establish how an eHealth application could provide support. This investigation used social media to reach the cohort 'where they were', without needing to undertake traditional software requirement extraction. The study demonstrated that social media can be used as an effective research tool, not only as a data collection tool to gain insight for a possible mobile application prototype development, but it has demonstrated that social media is a feasible participation tool of User Centred Design (UCD) engagement.
\end{abstract}

\section{Introduction}

Software produced without due attention to its users' needs is doomed to fail. Engaging users within the design process is key to their successful adoption of the system, and adherence with the processes of the system [1, 2]. User-Centred Design (UCD) [3] methodologies have grown in popularity for their ability to enable users needs to be met within systems that are built to meet their needs. However, UCD requires a deep understanding of who will be using the system embedded into all stages of a systems development lifecycle [4]. These efforts require access to users, interaction on design elements, and multidisciplinary teams, which results on an increased overhead on the design process and is often overlooked. In some contexts, including the one examined in this paper, users are largely inaccessible to designers, resulting in undertaking a UCD based design methodology extremely challenging.

There is a myriad of examples that exhibit the failure to adhere to these UCD design principles, and the impact that this lack of adherence has on the effective adoption of technology systems, and compliance with the tasks required within those systems [5]. Despite this history, we still see a lack of UCD focus in the design of systems of such vital importance as those that seek to improve educational, health, and even environmental outcomes. One example domain where we see a lack of adoption and adherence of developed technical systems is that of mHealth systems.

The usefulness of Information Technology to provide individualised care has long been suggested [6], and the number of applications being produced reflects a market response to this opportunity. In 2017 it was reported that there were approximately 325,000 mHealth apps [7] and it has been estimated the market will grow to a value of 150 billion USD in 2026 [8].

The potential of mHealth to enable users to gain access to knowledge and tools to enable better health outcomes without needing a medical practitioner present is seen as a simple solution to an important problem. However, the efficacy of these interventions has been shown to be limited, as described by Marcolino et al [9] who conducted a systematic review of 371 studies and nearly 80,000 patients. This review reported that while some technical systems were shown to be having positive improvement in asthma patients, attendance rates, and increased smoking abstinence rates, a large range of less successful outcomes were also being reported.

In investigating the lack of successful outcomes of such a vast range of mHealth technical solutions, many researchers have sought to understand this phenomenon [10-12], and have learnt that this lack of adoption and adherence is not due to a lack of demand for such solutions, but because the applications had not been designed according to the needs of users. These include a general failure of published studies of mHealth solutions to report any design approaches or usability evaluations used in the creation of their IT interventions [12], and those that do report on design indicate a heavy reliance on the insights gained from clinicians, rather than users $[13,14]$.

Both Baker et al [13] and Torus et al [14] proposed a range of solutions to improve intervention outcomes, both of which highlighted the need to be more user focused when creating an intervention. However, 
developing health interventions within an IT usercentered design framework is not a simple task, adding additional time and costs to the development and requiring access to the users of the intervention. Given that many potential users of an mHealth intervention may be inaccessible - either due to the stresses of their medical condition, restriction of access through health care providers, their time availability, or their physical remoteness - a solution to gaining their insight needs to be developed. If we are able to access traditionally unavailable users of potential mHealth solutions, then designers will be able to better understand the context of the potential solution and develop a more comprehensive set of user requirements than those that can be hypothesised by clinicians, however wellinformed these clinicians may be. With a better understanding of user requirements, solution designers have better tools to build appropriate functionality to support the perceived usefulness of the solution, as well as appropriate interface design to support perceived ease of use - two elements that the Technology Acceptance Model $[15,16]$ suggest are core to achieving adoption of a technical solution.

This paper describes one approach to sourcing requirements from traditionally unavailable users social media systems. In the following sections of the paper we describe a case example of the need to understand the context of users as the first step in the development of an mHealth application to support carers of children with autism, and how reviewing social media posts has provided interesting insights towards developing a contextual understanding and gathering requirements from users that are not traditionally accessible given the high demands of fulfilling their carer role.

\section{2. mHealth for Carers of Children with Autism}

Autism Spectrum Disorder (ASD) describes a group of neuro-developmental disabilities which cover a wide range of symptoms and has an estimated prevalence that has increased dramatically across the globe over the past two decades [17]. In Australia, according to the Australian Bureau of Statistics there are 205,200 Australian with ASD (106,600 are aged 5 to 20 years), as compared to 64,400 in 2009 [18, 19]. The substantial increased in ASD prevalence has created a direct impact on the demand and expectations for professional clinical services and non-professional caregiver's support [20].

One of the society's greatest assets is the many family members who provide care to ill or disabled family members. The National Alliance for caregiving found that the vast majority of healthcare is provided by the families, and not the healthcare professionals [21]. There has been three decades of research focusing on caregivers in general [22], noting that informal caregiving represents a considerable economic saving for society though often at a cost for caregivers [22]. Caregiving is associated with various negative outcomes including diminished physical and psychological health, lessened capacity to attend to their own health needs, and restricted ability to participate in social and economic activities [23-26]. Carer burden is a multifactorial construct that encompasses physical, psychological, emotional, social, and financial impact of the caregiving role, as well as carers' perceptions of their coping. Carer burden is generally higher when caregivers have pre-existing poor health and fewer economic resources [27].

The high level of stress, depression, anxiety, disruptive sleep and fatigue, that the parents of ASD children report, are caused by the extensive challenges they face as the primary caregiver including inadequate level of support, the child's challenging behaviour problems, public misconception of the condition, exhaustion, a lack of coping strategies, and the quality of information sources to support for their needs.

In this instance, mHealth support tools appear to offer opportunities to assist the needs of this carer group, however, a review of mobile applications or internetbased support tools for these carers during $2018 \mathrm{Lim}$ [28] uncovered only four examples focused towards the needs of this carer group. The functionality included in these four tools was assessed by Lim, who concluded that these tools included a diverse set of functions ranging from peer support to experience sharing, yet the only feature common across all four support tools was educational information on the condition. Furthermore, these tools had been downloaded by only a very small proportion of carers (with only 10,000+ downloads for one of the tools, and the others with less than 5000+ downloads). Analysis across these apps also indicated that these had been developed primarily by nonprofessional caregivers who were trying to fill a gap and support their own community. None of the tools had been developed with the insight provided by technical designers with a focus towards usefulness and usability.

A need remains therefore to explore the needs of this carers group in more detail, and to build this knowledge into mHealth tools to support this cohort. The challenge however exists of how to learn about the needs of this carers group when they are time-poor, under emotional pressure, and can be located across a large geographic area. This knowledge can then inform whether an mHealth app is suitable, and if so, what features it needs to fill a support gap for the cohort.

The approach taken by the authorship team was to go to where the carers were - that is, to review the social 
media posts of carers with children with ASD. Researchers are beginning to exploit social media platforms as a research tool where a rich source of publicly available online data, such as user's behavioural patterns, expression of thoughts, likes, sentiments, and preferences, can be gathered and studied [29]. Social media provides an accessible online platform where users, including caregivers, can create and publicly share real time user-generated content while interacting with other users, and so these posts can be analysed as a source to discover: the challenges that a non-professional caregiver faces while caring for child with ASD; and the support needed by non-professional caregivers of a child with ASD.

\section{Developing user requirements though social media platforms}

Social networks have become extremely popular in the last decade. They are not simply a place for users to communicate with friends and family, but to also discover information. This research is aiming to reach a target cohort who are time poor but face a complex set of needs. This paper describes a process of requirements elicitation from social media posts to then inform the creation of eHealth-based interventions to serve the cohort.

The concept of using Social Networks to undertake requirements elicitation is not new [30-32] with the platforms being used for this shortly after their creation. However, this is commonly a way of reaching out directly to users and asking them for input. The method involves formally eliciting their input, to describe the needs that they have. Such a process, while active in nature, requires time from the target group to participate. The requirement of time can result in low engagement from the target users, with some individuals being overrepresented unless done gradually over time [33].

The work presented in this paper takes a more passive approach, to gather requirements through observation rather than explicitly elicit them. This enables the target cohort to be reached without taking up their time, of which they don't typically have an excess of. The aim here is being able to 'reach the unreachable'. To support those most in need of support. The work was undertaken with approval of the Human Research Ethics Committee (Tasmania) network (H0017201).

\subsection{The extent of usage of social media platforms by the target cohort}

A 2017 report into social media usage found that $84 \%$ of Australians access the Internet daily and $79 \%$ of these Internet users use social networking sites, with $94 \%$ of social networkers using Facebook, $46 \%$ using Instagram, and 32\% using Twitter [34]. The simple design and high accessibility of social media platforms is the key factor that in their use which is transforming how people access, receive and share information about health and health care [35], including personal experience [36].

Research has found that people are engaging with health-related social media groups, such as special interest Facebook groups, to learn and share healthcare knowledge [37]. It was further noted that this includes mothers of children with specific health conditions were highly engaged in special interest groups to seek information and peer support from other parents with similar experience on how to cope with a specific health problem [38].

Studies have demonstrated that most individuals are seeking peer support in managing their own health condition or parenting role [39]. The accessibility of social media platforms has therefore, allowed individuals to receive emotional support and learn from shared experience [40]. Research has further shown that due to the challenging behaviour of an ASD child and the lack of social support, caregivers are utilising fewer and fewer face-to-face support services and have begun to turn to social media platforms that do not require physical presence to seek support [41-43].

In 2018, the authors surveyed a small group of carers with children with ASD $(n=40)$ who responded very strongly to the statement "I use social media (i.e. Facebook, Twitter, Instagram)". 70\% of respondents said that they used it all the time, with none of the respondents saying that they never used one of the platforms. This response, in conjunction with prior work by others [44] surveying using social media platforms as a data gathering tool then motivated this authorship team to review these platforms as a mechanism of understanding carer's current support needs.

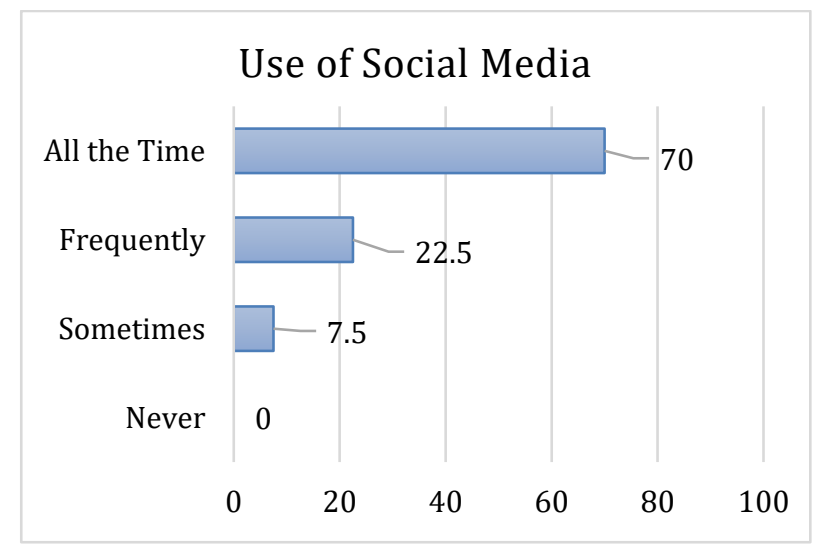

Figure 1: ASD Carer's responses to Use of Social Media Platforms 


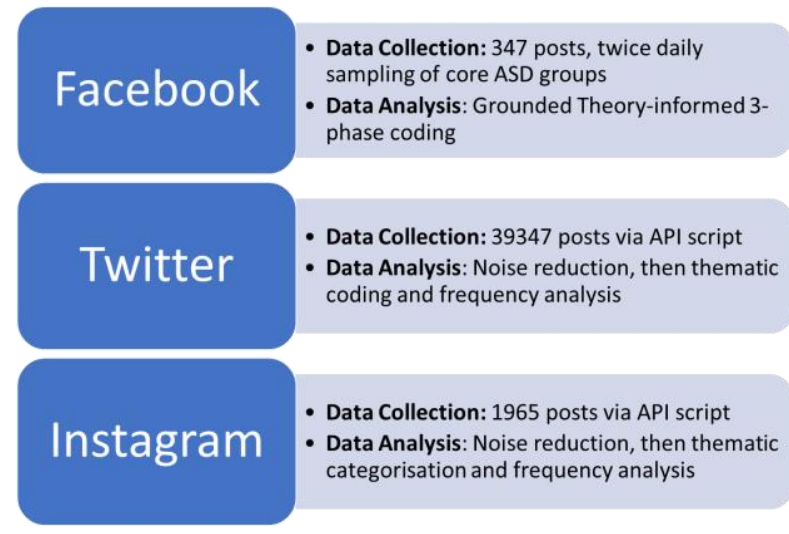

Figure 2. Data collection and analysis procedures

\subsection{Procedure for collecting and analysing social posts}

In order to capture the highest possible rate of social media posts from carers, Autism Awareness Month [45] was selected as the core data collection period, in which posts from the three largest social media platforms - Facebook, Twitter, Instagram were collected and analysed (Figure 2).

Facebook was selected as it boasts 2.45 billion users worldwide and provides users with opportunities to write freeform on their personal pages or to community pages relevant to their interests [46]. Given that the authorship team was acutely interested in learning about the challenges and needs of the carer group, these self-expression posts and community discussions would provide vital insight.

Facebook data was collected on a twice daily ( 8 am and $8 \mathrm{pm}$ ), by visiting several public Autism support groups on Facebook (Figure 2). The top three 3 posts were collected based on the greatest number of interactions (number of 'comments' and 'likes'). A total of 347 posts were recorded during Autism Awareness Month. As the data collected from Facebook group and questionnaires was verbatim, a three-phase coding system, informed by Grounded Theory [47, 48] was employed to analyse this data.

1. Open coding assigns contextual labels to data

'chunks' by segmenting data into meaningful

expressions and describing them in single words or short sequence of words.

2. Axial coding relates codes (categories and concepts) to each other, via a combination of inductive and deductive thinking.

3. Selective coding is where previously identified discrete concepts and categories are further defined, developed, and refined and then brought together to tell a larger story.
Guided by a bottom-up grounded theory approach [47-50] our analysis of the Facebook posts was undertaken as described (through a brief example) in Figure 3.

Firstly, each post was extracted directly from Facebook. The first post shown in Figure 3 and represented in the first column of the figure was posted on Facebook within the publicly accessible group named 'Autism Parent Support \& Discussion Group' on the $19^{\text {th }}$ March 2018 by a male parent. This post was reviewed, and open codes were assigned to this post to open the data to researcher-interpreted labels of meaning. For example, the raw post data 'I' $m$ tired. I put on a facade because I need to. Someone has to be the strong one..." was interpreted as: exhaustion, needing to hide real emotions, and need to be reassuring. The sentence "I'm sorry. Just having a bad day and needed to vent" has been assigned codes of meaning such as: apologetic for failing, need emotion support from community, and explaining emotions as 'a bad day'. These open codes provide a starting point to understanding the data being reviewed from a more abstracted perspective.

Secondly, connections between the open codes were identified in a process known as axial coding (shown in the third column of the figure). Open codes are grouped together under a meaningful umbrella term that draws connections between them. For example, the open codes of: needing to hide real emotions, can't be themselves, and not emotionally ok, have all been grouped together as examples of the poster's selfreported perception of their inability to cope, as well as their exhaustion and their feelings of being overwhelmed.

In our fourth post shown in Figure, we repeat this process. For example, the post by a female parent to the Facebook group 'ASD Matters' on 23 March 2018 consists of the text "he has amazed us so much. His report from his teacher makes my heart sing and I never in a million years would have thought he would ever be able to attend reward days BUT he can \& he is" has been assigned the open codes of: sharing of joy, and child's progression. Furthermore, the statement that "we are very lucky to have an amazing teacher with some understanding \& awareness of Autism and can see the triggers. The whole school have been very excepting \& helpful" has been assigned open codes of compliment and conformation of school, and autism knowledge". In turn these four open codes have been abstracted as examples of: joy, scenario description, and positive achievement.

These two stages of open and axial coding were applied across all 350 Facebook posts. Following this, the axial codes across all posts were analysed and 


\section{Direct Facebook post}

tired. I put on a facade because I need to. Someone has to be the strong one...to say everything will be ok. I put on a front for my non verbal daughter. I put one on for her Juther, to my family, to the women I date. I act like I have my \$@? \& together and it's Just simply not true. Im a mess. I worry about my daughter constantily. How she will parents having full blown conversations with their toddlers and I yearn for that. Now she's just happy l understand some words she says and she repeats them over ad .

ave cried so much today. Today was my son 4th Birthday party and of course he had et an attitude all he is wondered about is how I talked to him....not our son. Sometimes, don't know if I am strong enough for this? Is my marriage strong enough for this? Does lever get easien hove my Son so much and lib

t looking for some help. My nearly 18 year old daughter, who has been diagnosed Shool and getting ariety, has for the last 4 years been running off to the local primary the school and making poor choices and getting arrested. I a m just needing suggestions as to what you oth
situations like this.

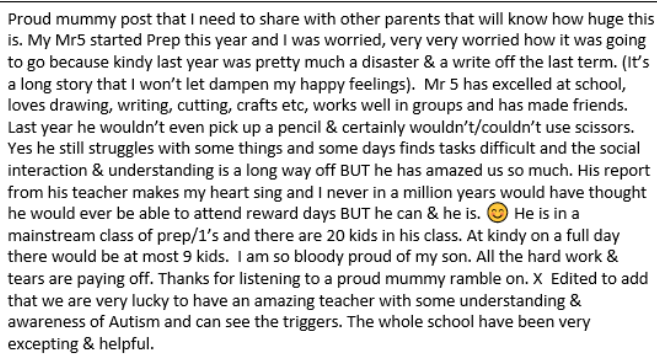

Figure 3. Data collection and analysis procedures
Example Open Codes from Post

Overwhelmed with caring, reeding to hide

need to be reassuring to

can't be themselves,

cting ok,

not emotionally ok,

concern for long-term wellbeing of child, vearns for normal interactions

apologetic for 'faling

need emotional support from community

explains response as 'bad day'.

\section{personal emotional response}

scenario description

ack of emotional support,

ot able to express real emotio

lack of family cohesion

questioning streng

questioning the future

expression of hopelessness

need for emotional suppo

request for help

age description,

multiple diagnosis

problem identification

need behaviour modification help

symptom identification
information seeking

looking for practical advice

\section{sharing of jor}

child's progression

mation of schood
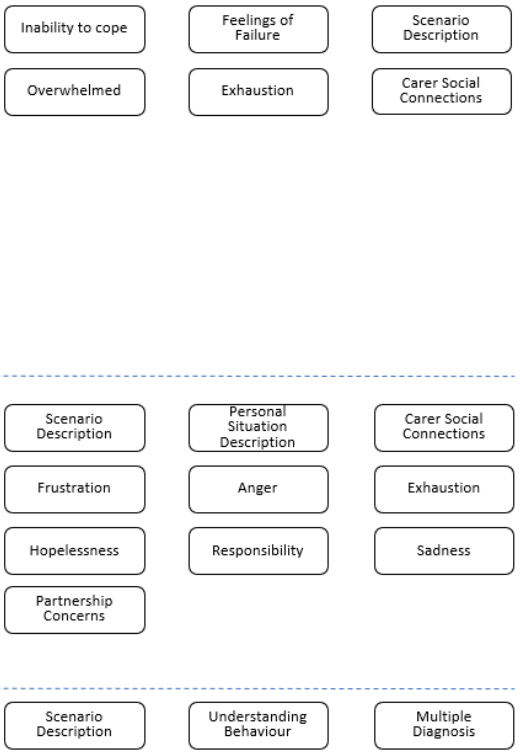

Understanding
Behaviour

Multiple
Diagnosis

autism knowledge
Preliminary Themes from Example

Axial Codes

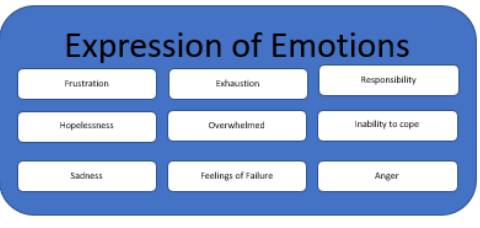

Information Seeking

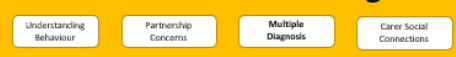

Seeking Shared Experiences 
further grouped into categories that thematically encapsulated their meaning to explain the needs expressed by carers of children with autism. A brief example of this final step is shown in the final column of Figure 3 in which the axial codes from the four example posts are thematically grouped as examples of either a poster's: expression of emotions, their information seeking, or their need to share their experiences.

This approach applied to our Facebook data set resulted in the identification of a core set of carer needs and carer challenges described in Figure 4 (next page).

Twitter reports 330 million users and allows for the posting of short-form free text expressions, as well as allows the linking of conversations amongst users [51]. Given we were interested in learning from the community of the carer cohort, we were especially interested in observing the conversations and discussions held between members of this community. Similarly, Instagram has 1 billion users worldwide and allows users to post visual images and short videos to their followers, with a short self-expression text element to describe the image [52]. Again, a carers selfexpression was of interest to this study.

Both Twitter and Instagram posts were collected, again, during Autism Awareness Month in 2018. A series of accounts on both platforms were 'followed' that provided information and support to autism sufferers or carers of people with autism. Posts were extracted via a simple script making call to the application programming interface on both platforms. A total of 39,347 posts were collected on Twitter, and 1965 on Instagram. Given that this data was in shortform only, often as only a few words rather than full sentences, data was not subjected to the same thematic analysis as the Facebook data, but rather a more simplified categorisation process: that removed words with no specific meaning or stop-words; grouping words with same expression/meaning; categorising word groups; and developing abstract themes from word groups. The outcome of these analyses is represented in Figure 4 (next page).

\section{Results of the social media posts of carers of children with ASD, during autism awareness week}

The application of the grounded-theory threephase coding method to the 347 Facebook posts identified three thematic areas that the carers of Carers of Children with ASD were posting about during Autism Awareness Week 2018. As can be seen in Figure 4 , our carer cohort was posting to express a range of emotions regarding their carer role; to seek information; and to share their own experiences or learn about those of other carers in their community. Facebook posts and discussions provided the broadest range of conversation topics, perhaps due to the longer free-form text options, and established groups dedicated to the community of carers with children with ASD. Specifically, via Facebook, carers were expressing positive emotions such as Joy, but a much stronger expression of negative emotions such as Exhaustion, Frustration, Loneliness, and Sadness through their posts. They were using Facebook to seek information from other carers on understanding the diagnosis of the child under their care, education options, understanding challenging behaviours, and where to seek social support and connectedness. They also used Facebook to share their own experiences of being in a carer role - describing their personal situations, or a specific scenario, or seeking to share a positive achievement.

Twitter posts similarly ran across these three themes, but the posts were more focused towards the expression of emotions, than information seeking and experience sharing. As Twitter posts are short-140character expressions, many of these posts were targeted towards expressing a specific negative emotion such as Anxiety, Stress, Depression, Sorrow and Worry, although positive expressions of Love, Hope, and Joy were also recorded. Twitter was a source of seeking information on social support, education options, financial matters related to their carer's role, and understanding the diagnosis of the child under their care, however to a lesser extent than Facebook.

Instagram posts again were targeted towards expressing emotions, similar in nature to those posted on both Facebook and Twitter, and towards using the platform to describe their own personal circumstance.

\section{Discussion and Limitations}

These findings identify the challenges expressed by carers of children with ASD, in their own words. No contact with actual carers was required to gain this insight, and yet we have a solid foundation to begin understanding what mHealth designers need to be aware of in order to build tools that are perceived as useful to this career group. Specifically, this analysis provides insight that mHealth tools must include the following:

- Features to support an expression of emotion;

- Features to support the sharing of experiences;

- Features to support the development of social connectedness; and

- Features to support the provision of information (financial, medical, social, educational, and emotional) 

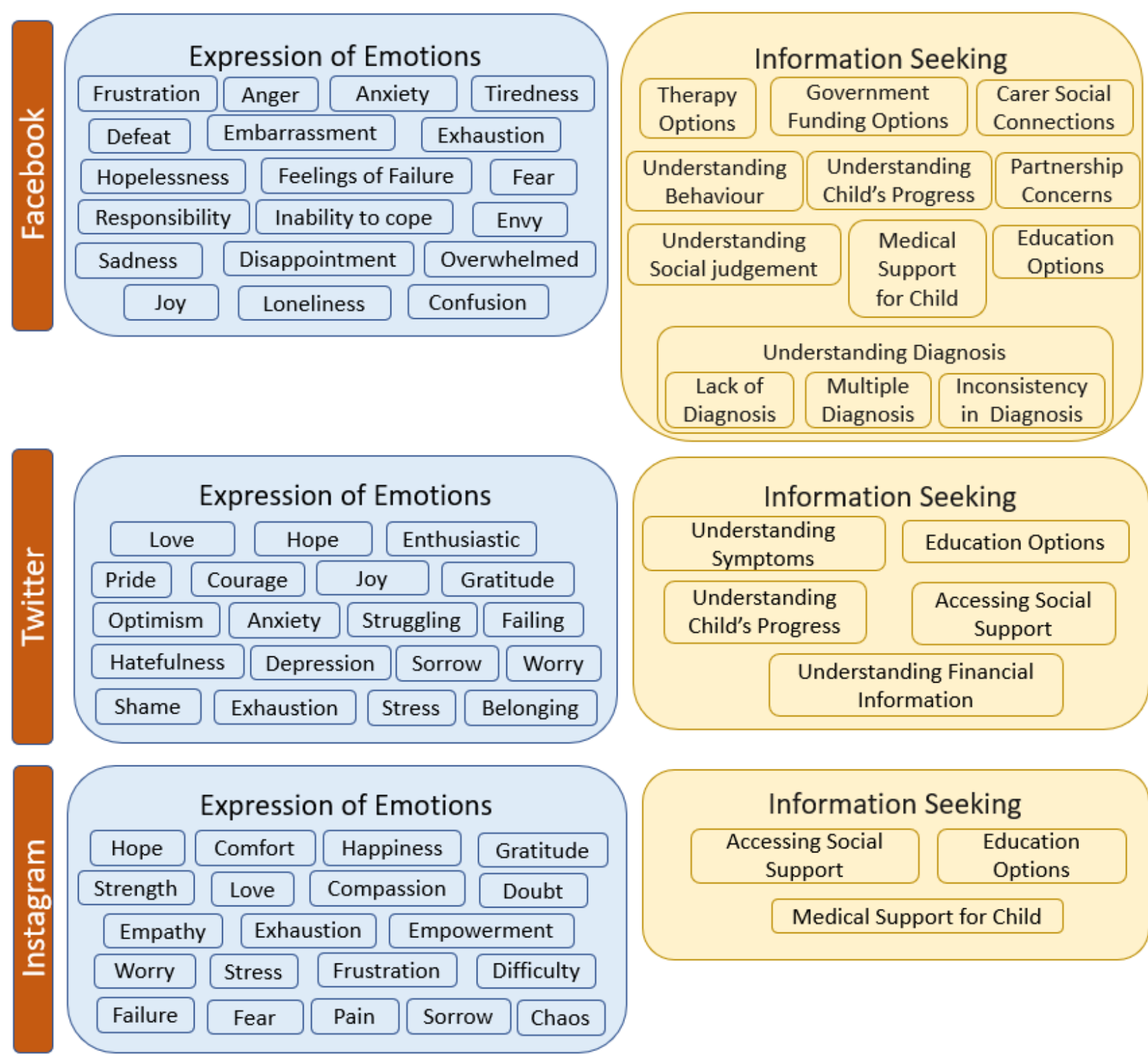

\section{Seeking Shared Experiences}

Positive Achievement

Scenario Description
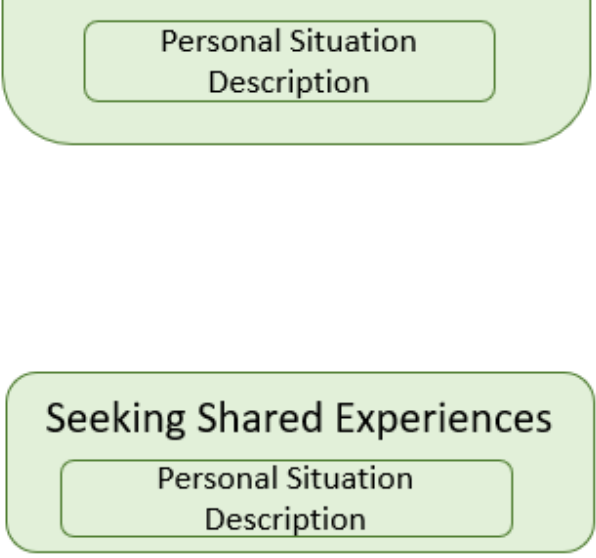

\section{Seeking Shared Experiences} Personal Situation Description

Figure 4. Summary of Categorised Results of Facebook, Twitter, and Instagram Posts. 


\begin{tabular}{|c|c|}
\hline User Needs from Social Media Posts & User Needs from Online Survey \\
\hline Features to support an expression of emotion; & \\
\hline \multicolumn{2}{|l|}{ Features to support the sharing or experiences; } \\
\hline $\begin{array}{l}\text { Features to support the development of social } \\
\text { connectedness; and }\end{array}$ & A platform to connect with other carers \\
\hline $\begin{array}{l}\text { Features to support the provision of information } \\
\text { (Financial, medical, social, educational, and } \\
\text { emotional) }\end{array}$ & $\begin{array}{l}\text { - Information about ASD; } \\
\text { - Information about planning for the future; Advice } \\
\text { on relaxation techniques; } \\
\text { - Information about how to regulate one's own } \\
\text { emotions and thoughts; } \\
\text { - Information about how to care better for yourself. } \\
\text { - Information about managing difficult behaviours. }\end{array}$ \\
\hline
\end{tabular}

Table 1. Comparison of needs between Social Media analysis and online survey.

While the use of social media posts certainly appears to be a good opportunity to develop a set of user needs to commence the design of mHealth tools from this study alone, we must compare our insights to those collected by more traditional approaches to validate our approach.

In 2018 the authors sought to engage carers of children with ASD through an online survey to determine the challenges of carers of children with ASD, and their perceived usefulness of mHealth tools to support their needs. Sadly, only received 40 full responses to their survey, perhaps reflective of the time-poor characteristic of carers as already identified earlier in this paper. Descriptive statistical analysis of these respondents indicated that they were: nearly always or quite frequently stressed (69\%), providing caring services across morning, afternoons, and evenings (79\%), and they were only partially or not at all satisfied with the support services currently available to them (82\%). These carers expressed interest in using an mHealth tool to support their needs "Immediately after I learned of it" (28\%) or "Once I see some benefit to me using it" (59\%). When specifically asked what functions should be included in the design of a mHealth tool to support their needs, [28] reports they identified the following:

- Information about ASD;

- Information about managing difficult behaviours;

- A platform to connect with other carers;

- Information about planning for the future

- Advice on relaxation techniques;

- Information about how to regulate one's own emotions and thoughts;

- Information about how to care better for yourself.

These user needs can be compared to those achieved through the analysis of social media posts (Table 1), and we can see that while both sources of data collection identified a need for better information provision, our analysis of the carers' use of social media tools provides deeper insight into the need to include features to support emotional expression, and the sharing of personal experiences.

This comparison has allowed us to see that while full interaction with a user cohort is naturally the best way to elicit user requirements, in a population that is time-poor and emotionally distressed the analysis of social media posts provides useful insights in the absence of these users, and provides deeper insights towards user needs than that which can be obtained by surveys alone. This broad comparison is highly transferable to other contexts in which access to a target cohort is limited. Interviews to ascertain needs or requirements are time intensive and therefore limited. Survey participation has its own challenges and recruiting participants who are known to be time poor then reflects in the response rate, and therefore the applicability of the outcomes. Social media's high accessibility across a broad range of contexts and interest groups translates to it being a useful tool in requirements analysis in many areas, and not just autism or eHealth.

It is important to acknowledge the inherent bias in assuming an mHealth tool is needed by this or any other hard to reach cohort however the intent of this paper is to explore if the use of social media could result in meaning insights from hard to reach target users. The discussion of if the perceived need fits the cohort is a subject for another paper.

One limitation of this current study is that the data was gathered from publicly accessible groups. We acknowledge that carers may also subscribe to private groups where a different set of concerns are discussed in a more private environment and these privately disclosed concerns may differ from those able to be collected publicly. There is therefore potential that the use of social media to elicit system requirements may still not capture a full set of needs, yet our study has shown that there is indeed improvement in our insights 
when we engage with publicly available posts, rather than rely on traditional population data collection methods such as surveys, and that such attempts to better understand the needs of vulnerable and unreachable groups is worthy of being undertaken.

A further limitation of the study was that the observation of the cohort was undertaken during a limited time frame of 4 weeks. This is a small snapshot within their annual routine and may not fully capture the variation that occurs through a year with school terms and holiday time. Additionally, as the observations were limited to public Australian social media posts, and over the short time frame, this limited the observation to only 347 Facebook posts, which is a smaller dataset than that collected for Twitter or Instagram. A longer observation window could have enabled more insights to be gained from a larger dataset.

\section{Conclusion}

User-Centered Design (UCD) is the best practice framework that is commonly adopted in production of products, including software, to ensure the resulting output is of high usability and that it addresses users' needs. However, when the target users are hard to reach within a traditional development cycle, this will result in the design occurring without the needed stakeholder input. As a result, we see many applications, and specifically mobile health applications where UCD is absent.

This paper has presented a study where social media was used to ascertain the unmet needs for a cohort of users who would be traditionally hard to reach. Time pressures due to being in a caring role to a minor with a serious medical condition results not only in a stressful living environment, but also, understandably, little time to participate in the design process for software. This cohort was used as a pilot case to explore what the need are of a complex cohort, to see whether a less invasive requirements analysis could be undertaken. The outcomes were compared favourably to those which were also collected through a more traditional approach.

Social media and mobile health applications are not a trend, but a common accepted part of modern IT usage. This study has shown social media platforms can be leveraged to improve the quality of mobile health applications and the support that they provide.

\section{References}

1. Ehn, P. and M. Kyng. The collective resource approach to systems design. in Computers and democracy. 1987. Gower Publishing.
2. Bødker, S., Creating conditions for participation: conflicts and resources in systems development. Humancomputer interaction, 1996. 11(3): p. 215-236.

3. Norman, D.A. and S.W. Draper, User Centered System Design; New Perspectives on Human-Computer Interaction. 1986: L. Erlbaum Associates Inc. 526.

4. ISO, Ergonomics of human-system interaction - Part 210: Human-centred design for interactive systems. 2019, International Organisation for Standardisation.

5. Bogner, M.S., Human error in medicine. 2018: CRC Press.

6. Ortiz, E., C.M. Clancy, and Ahrq, Use of information technology to improve the quality of health care in the United States. Health services research, 2003. 38(2).

7. Research2Guidance. 325,000 Mobile Health Apps Available in 2017. 2017; Available from: https://research2guidance.com/325000-mobile-health-appsavailable-in-2017/.

8. Acumen. mHealth Market - Global Industry Size, Share, Trends and Forecast 2018 - 2026. 2018; Available from: https://www.acumenresearchandconsulting.com/mhealthmarket.

9. Marcolino, M.S., et al., The Impact of mHealth Interventions: Systematic Review of Systematic Reviews. JMIR Mhealth Uhealth, 2018. 6(1): p. e23.

10. Ranney, M.L., et al., Emergency Department Patients' Preferences for Technology-Based Behavioral Interventions. Annals of Emergency Medicine, 2012. 60(2). 11. Birnbaum, F., et al., Patient engagement and the design of digital health. Academic emergency medicine: official journal of the Society for Academic Emergency Medicine, 2015. 22(6): p. 754

12. Schnall, R., et al., A user-centered model for designing consumer mobile health (mHealth) applications (apps). Journal of Biomedical Informatics, 2016. 60: p. 243-251.

13. Baker, T.B., D.H. Gustafson, and D. Shah, How can research keep up with eHealth? Ten strategies for increasing the timeliness and usefulness of eHealth research. Journal of medical Internet research, 2014. 16(2): p. e36.

14. Torous, J., et al., Clinical review of user engagement with mental health smartphone apps: evidence, theory and improvements. Evidence Based Mental Health, 2018. 21(3). 15. Davis, F.D., Perceived usefulness, perceived ease of use, and user acceptance of information technology. MIS quarterly, 1989: p. 319-340.

16. Davis, F.D., R.P. Bagozzi, and P.R. Warshaw, User acceptance of computer technology: a comparison of two theoretical models. Management science, 1989. 35(8): p. 982-1003.

17. Christensen, D.L., et al., Prevalence and Characteristics of Autism Spectrum Disorder Among Children Aged 8 Years - Autism and Developmental Disabilities Monitoring Network. MMWR Surveill Summ, 2012. 65(3): p. 1-23.

18. Statistics, A.B.o. 4430.0 - Disability, Ageing and Carers, Australia: Summary of Findings. 2018; Available from:

https://www.abs.gov.au/AUSSTATS/abs@.nsf/Lookup/443 0.0Main+Features102018? OpenDocument.

19. Australian Bureau of Statistics. Autism in Australia. 2012 viewed 13 September 2017]; Available from: http://www.abs.gov.au/ausstats/abs@.nsf/Latestproducts/44 
28.0Main \%20Features32012?opendocument $\&$ tabname $=\mathrm{Su}$ mmary \& prodno $=4428.0 \&$ issue $=2012 \&$ num $=\&$ view $=$.

20. Steyaert, J.G. and W.D.L. Marche, What's new in autism? European Journal of Pediatrics, 2008. 167:

21. Adler, R., Mehta, R., Catalyzing Technology to Support Family Caregiving. 2010, National Alliance for Caregiving. 22. Hokanson, L., et al., A systematic review of Indigenous caregiver functioning and interventions. Quality of Life Research, 2018. 27(8): p. 2007-2017.

23. Cummins, R., et al., The Wellbeing of Australians-Carer Health and Wellbeing (Australian Unity Wellbeing Index Survey 17.1). Melbourne, Victoria: Australian Centre on Quality of Life, Deakin University, 2007.

24. Kenny, P., M.T. King, and J. Hall, The physical functioning and mental health of informal carers: evidence of care-giving impacts from an Australian population-based cohort. Health \& social care in the community, 2014. 22(6). 25. Pinquart, M. and S. Sörensen, Differences between caregivers and noncaregivers in psychological health and physical health: a meta-analysis. Psychology and aging, 2003. 18(2): p. 250.

26. Robison, J., et al., A broader view of family caregiving: effects of caregiving and caregiver conditions on depressive symptoms, health, work, and social isolation. Journals of Gerontology Series B: Psychological Sciences and Social Sciences, 2009. 64(6): p. 788-798.

27. Pinquart, M. and S. Sörensen, Ethnic differences in stressors, resources, and psychological outcomes of family caregiving: A meta-analysis. The Gerontologist, 2005. 45(1): p. 90-106.

28. Lim, D.T., An investigation of the feasibility of social media platform to gain insight to design a mobile application prototype that can facilitate the support needed by the non-professional caregiver of an ASD child., in School of Technology, Environments and Design. 2018, University of Tasmania. p. 130.

29. Mahrt, M. and M. Scharkow, The Value of Big Data in Digital Media Research. Journal of Broadcasting \& Electronic Media, 2013. 57(1): p. 20-33.

30. Storey, M.-A., et al. The impact of social media on software engineering practices and tools. in Proceedings of the FSE/SDP workshop on Future of software engineering research. 2010.

31. Groen, E.C., J. Doerr, and S. Adam. Towards crowdbased requirements engineering a research preview. in International Working Conference on Requirements Engineering: Foundation for Software Quality. 2015. Springer.

32. Brabham, D.C., Crowdsourcing as a model for problem solving: An introduction and cases. Convergence, 2008. 14(1): p. 75-90.

33. Levy, M., I. Hadar, and D. Te'eni. A gradual approach to crowd-based requirements engineering: The case of conference online social networks. in 2015 IEEE 1st International Workshop on Crowd-Based Requirements Engineering (CrowdRE). 2015.

34. Sensis. Sensis social media report 2017: chapter 1Australian and social media. 2017; Available from: https://www.sensis.com.au/asset/PDFdirectory/SensisSocial-Media-Report-2017.pd.
35. Eysenbach, G., et al., Health related virtual communities and electronic support groups: systematic review of the effects of online peer to peer interactions. Bmj, 2004. 328(7449): p. 1166.

36. Ziebland, S. and S. Wyke, Health and illness in a connected world: how might sharing experiences on the internet affect people's health? The Milbank Quarterly, 2012. 90(2): p. 219-249.

37. Scanfeld, D., V. Scanfeld, and E.L. Larson, Dissemination of health information through social networks: Twitter and antibiotics. American journal of infection control, 2010. 38(3): p. 182-188.

38. Griffiths, F., et al., Social networks-the future for health care delivery. Social science \& medicine, 2012. 75(12).

39. Plantin, L. and K. Daneback, Parenthood, information and support on the internet. A literature review of research on parents and professionals online. BMC family practice, 2009. 10(1): p. 34.

40. Griffiths, F., et al., The impact of online social networks on health and health systems: a scoping review and case studies. Policy \& internet, 2015. 7(4): p. 473-496.

41. Siklos, S. and K.A. Kerns, Assessing need for social support in parents of children with autism and Down syndrome. Journal of autism and developmental disorders, 2006. 36(7): p. 921-933.

42. Weiss, M.J., Hardiness and social support as predictors of stress in mothers of typical children, children with autism, and children with mental retardation. Autism, 2002. 6(1)

43. Hamm, M.P., et al., Social media use among patients and caregivers: a scoping review. BMJ open, 2013. 3(5):

44. Cordoş, A.-A., S.D. Bolboacă, and C. Drugan, Social Media Usage for Patients and Healthcare Consumers: A Literature Review. Publications, 2017. 5(2): p. 9.

45. AutismSpeaks.org. World Autism Month. 2018; Available from: https://www.autismspeaks.org/worldautism-month.

46. Facebook, Facebook Reports Third Quarter 2019 Results. 2019.

47. Glaser, B. and A. Strauss, Grounded theory: The discovery of grounded theory. Sociology the journal of the British sociological association, 1967. 12(1): p. 27-49.

48. Strauss, A. and J. Corbin, Basics of qualitative research. 1990: Sage publications.

49. Walker, D. and F. Myrick, Grounded Theory: An Exploration of Process and Procedure. Qualitative Health Research, 2006. 16(4): p. 547-559.

50. Becker, P.H., Common Pitfalls in Published Grounded Theory Research. Qualitative Health Research, 1993. 3(2). 51. Twitter, Twitter Third Quarter 2019 Results. 2019.

52. Constine, J. Instagram hits 1 billion monthly users, up from 800M in September. Techcrunch 2018. 